\title{
Surface microsurgery: taper section preparation
}

\author{
J.A. Desport and M.J. Bennett
}

Surface Science and Technology Department, AEA Industrial Technology, B. 393 Harwell Laboratory, Didcot, Oxfordshire, OX11 ORA, U.K.

\begin{abstract}
Surface microsurgery is the science of preparing surface layers, such as oxide scales and coatings, for characterisation of their microstructure and composition, by conventional surface analytical techniques, such as SEM, EPMA, SIMS etc. A surface microsurgery procedure often employed involves the preparation of a taper section. Using relatively simple equipment, significant improvements have been made to the precision, and thus the effectiveness, of this procedure such that production of uniform, parallel cross sections, with magnifications in excess of 1000 , can be achieved readily and consistently. The procedure has enabled the detailed characterisation of $100-5000 \AA$ thick interlayers in composite coatings on both metallic and semiconductor substrates and also two-dimensional elemental analysis of micron thick oxide scales.
\end{abstract}

\section{Introduction.}

During the last two decades analytical techniques, of ever increasing sensitivity and precision, have become available for characterisation of the microstructure and composition of surface layers. The utilisation of such techniques, and in particular realisation of their full potential, is dependent on the ability to prepare specimens, such that the features required are revealed satisfactorily for examination. Numerous preparation procedures have been deployed and this branch of surface science may be described by a general title, surface microsurgery.

Most of the basic experimental procedures involved have been used by scientists in the corrosion and coating fields over many years, with each laboratory adopting its own empirical, ad hoc, approach. During the last five years work has been undertaken at the Harwell Laboratory aimed at improving the precision, and thereby the effectiveness, of these surface microsurgical procedures. Previous publications have described fractography [1] and selective etching [2]. The present paper will be concerned with taper section preparation, whose principal attraction lies in its ability to enlarge a transverse cross-section of a surface layer. Theoretically magnifications in excess of 1000 times should be possible (Fig. 1). This has been achieved now by the development of precision grinding techniques using relatively simple equipment.

Several examples will be given to demonstrate the unique advantages of this surface microsurgical procedure. On account of inadequate spatial resolution conventional surface analytical techniques, such as scanning electron microscopy (SEM), electron probe microanalysis (EPMA), secondary ion mass spectrometry (SIMS) etc., cannot be used normally to characterise 100-5000 $\AA$ thick interlayers. This can be tackled directly only using scanning transmission/transmission electron microscopy and then only on transverse electron transparent specimen sections, which are extremely difficult to produce. Use of the taper section preparation procedure however, has enabled the detailed characterisation of such interlayers on 


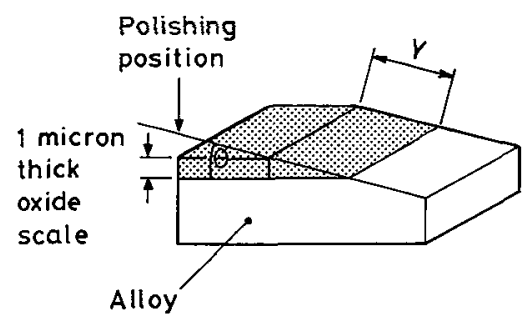

\begin{tabular}{|c|c|}
\hline $\begin{array}{c}\text { Taper section } \\
\text { length }(Y) \text { microns }\end{array}$ & $\begin{array}{c}\text { Taper angle } \\
\theta\end{array}$ \\
\hline 10 & $5^{\circ} 44^{\prime \prime}$ \\
100 & $34^{\prime \prime}$ \\
1000 & $3^{\prime \prime}$ \\
2000 & $1^{\prime \prime}$ \\
\hline
\end{tabular}

Fig. 1. - Angle of taper polishing required to magnify exposed through scale section.

both metallic and semiconductor substrates by SEM, EPMA and SIMS. The surface microsurgical procedure also has been deployed successfully to obtain crucial two-dimensional spatial elemental distributions in micron thick oxide scales by SIMS and an example of this will be described.

\section{Method of precision taper preparation.}

The experimental technique involved the use of a watchmakers lathe, modified into a precision lapping facility (Fig. 2) and a specimen mounting mandrel assembly (Fig. 3). The mandrel, fabricated from stainless steel, had a two arc unit goniometer head to provide precise, independent, movement in two dimensions. A small stainless steel platform, with a series of $0.5 \mathrm{~mm}$ wide open ended slots at right angles, was screwed onto the outermost arc unit for mounting specimens. Throughout processing the mandrel was positioned horizontally, on two wear resistant phosphor bronze bearing surfaces, within a cradle located on the crossslide of the lathe. The bearings also enabled mandrel movement laterally and about its own axis. For grinding operations two boxwood laps were specially constructed, which screwed successively into the lathe head stock. The laps had a series of $0.5 \mathrm{~mm}$ diam. $\times 0.5 \mathrm{~mm}$ deep holes to permit retention on their surfaces of water soluble diamond paste, on one of $3 \mu \mathrm{m}$ diam. and on the other of $1 \mu \mathrm{m}$ diam. Glycerol was applied to the surfaces to act as a lubricant and reduce friction during the lapping process. For final polishing the boxwood lap was changed to a cast iron plate onto which a self adhesive "Texmet" polishing cloth (Buehler Ltd.) was mounted and charged with $0.5 \mu \mathrm{m}$ diamond paste.

To prepare a typical specimen for taper sectioning, a small representative section $(\sim$ $3 \mathrm{~mm} \times 5 \mathrm{~mm} \times 5 \mathrm{~mm}$ ) was cut dry from the bulk material using a $0.5 \mathrm{~mm}$ wide silicon carbide wheel. Any burrs remaining on the specimen edges were removed using a small flat fine needle file: The specimen was washed in methanol and then air dried.

The mandrel was first aligned relative to the lap. For this purpose both goniometer arcs were set to zero and locked in position by screws provided. The mandrel was placed in the cradle and the platform surface was ground flat and square, using a $3 \mu \mathrm{m}$ diamond polishing lap, being finally thoroughly cleaned with water to remove the water soluble paste from the 


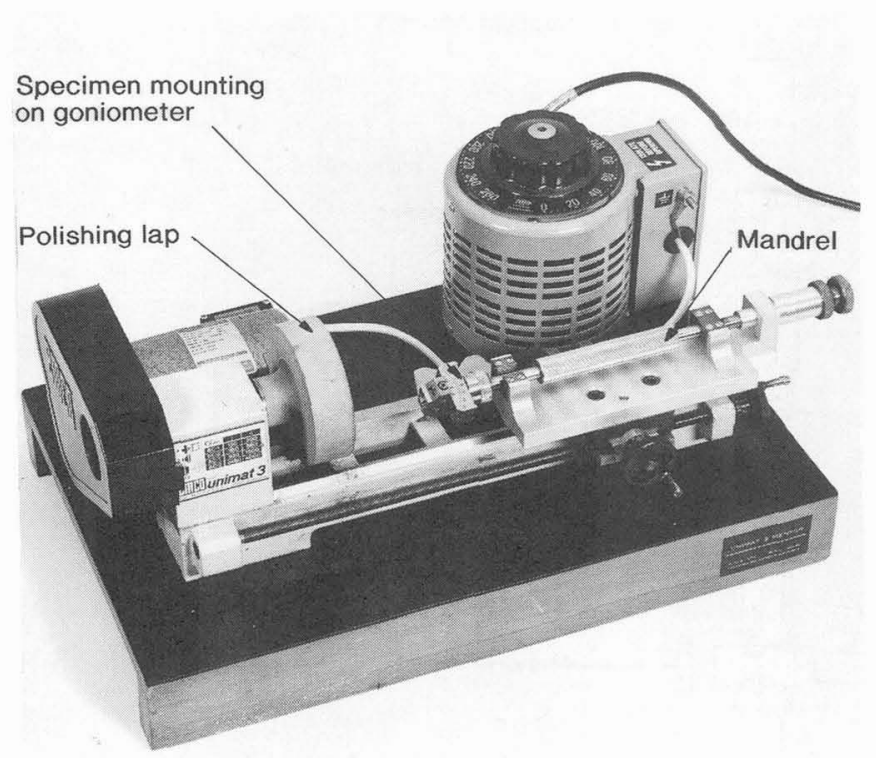

Fig. 2

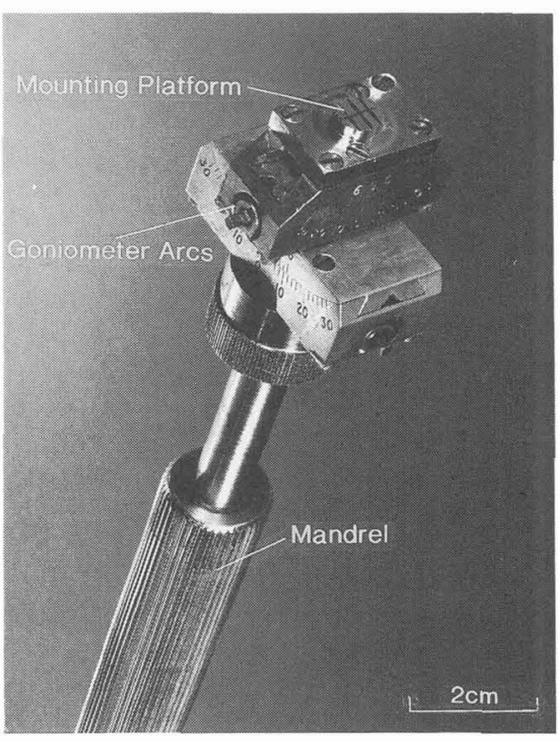

Fig. 3

Fig. 2. - Precision lapping machine for surface microsurgery.

Fig. 3. - Mandrel showing two goniometers arcs and specimen mounting platform.

channels. The mandrel was then fixed beneath a hot air blower and warmed to allow low melting point wax to flow onto the surface and into the slots. The specimen was located onto the wax such that its length was aligned in the rotational direction of the arc. Gentle pressure was applied to the specimen to squeeze out surplus wax from its underside, via the slots in the mounting platform. In order to initially align the specimen with respect to the abrasion lap surface the uppermost goniometer arc was offset to an angle of $\sim 5^{\circ}$ and locked in position. The mandrel was replaced in the cradle of the lathe and held by finger control until the specimen was oriented with its edge across the short face of the specimen in line with the lap surface. Lateral forward movement of the mandrel assembly by hand commenced the abrasion procedure. After $\sim 3$ minutes intermittent contact with the lap, revolving at $\sim 200$ RPM, the mandrel was removed and the specimen surface was cleaned for inspection in an optical microscope. This revealed that abrasion had taken place on one edge of the specimen only. Steps were then taken to position the specimen, by careful alteration of all both arcs of the goniometer, such that during subsequent processing all the specimen surface was inclined at the same angle to the polishing lap. This ensured the production of a uniform, parallel taper across the entire specimen width. At this stage consideration of the taper angle was possible by using the upper arc only as a means of control. Choice of the angular displacement was dependent on several factors relating to the material and the required extent of the depth investigation beneath its surface. The technique employed in developing a shallow taper section was to begin with a relatively steep angle of $\sim 2^{\circ}$, which after lapping was inspected in an optical microscope. The upper arc was then altered to $1^{\circ}$, the surface was relapped and again inspected. This process was reiterated until a taper section of the required 


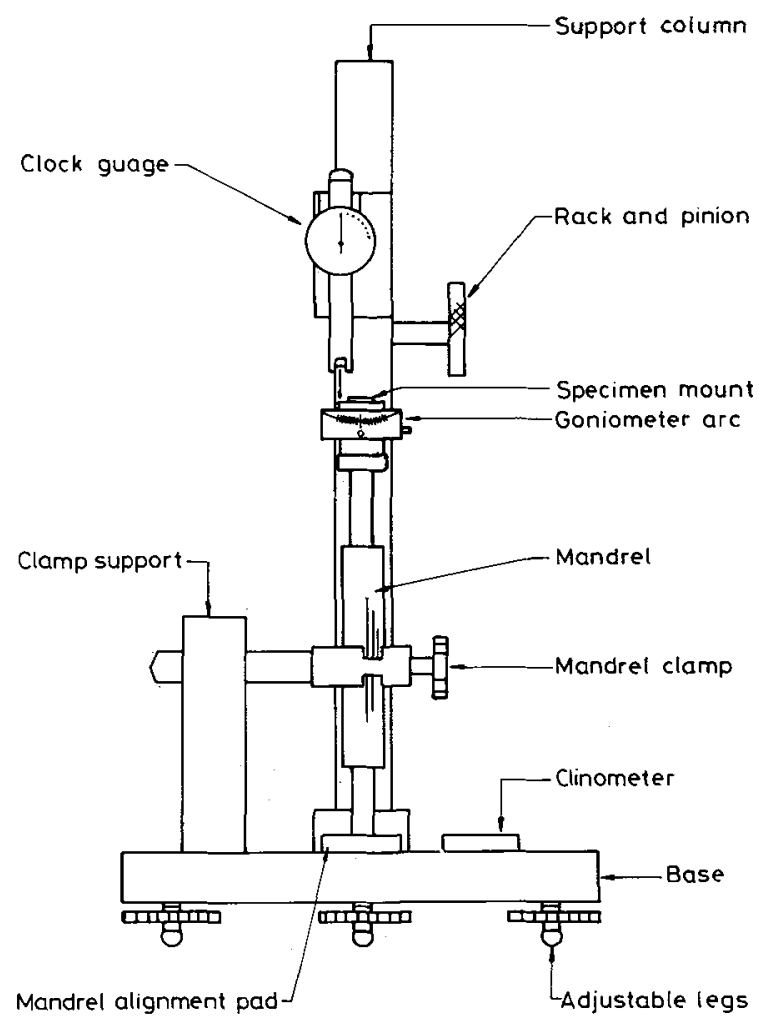

Fig. 4. - Stand with a clock gauge for the alignment of the goniometer arc.

angle was generated. Controlled precise and fine adjustment of the goniometer arc, to obtain progressively shallower taper angles, was achieved with the use of a clock gauge attached to a stand into which the mandrel was positioned (Fig. 4). Having obtained the required taper its surface finish was improved by polishing firstly, on $1 \mu \mathrm{m}$ diamond using the second boxwood lap and secondly, on $0.5 \mu \mathrm{m}$ diamond employing the cast iron lap and Texmet polishing cloth. Particular attention was directed to ensuring that after each stage of polishing the specimen and mandrel were thoroughly cleaned with distilled water to ensure removal of all traces of the diamond paste previously used. After the completion of polishing, the specimen was released from its platform using a hot air blower and then immersed in acetone to dissolve the residual wax before final cleaning in methanol. The specimen was then mounted in an appropriate holder for the required surface analysis.

\section{Use of taper section preparation for analysis of coatings and oxide scales.}

3.1 GHARACTERISATION OF A TiON INTERfaCial LAYER IN A COMPOSITE PACVD TIN-SiO 2 COATING. - The effectiveness of amorphous silica coatings, produced by plasma-assisted chemical vapour deposition (PACVD), in providing long term corrosion protection to many alloys has been extended to even higher temperatures and also to ferritic alloys by the use of a TiN interlayer produced by the same coating route [3]. To achieve optimum duplex 
coating performance, particular attention was directed towards maximising adhesion at both the substrate - TiN and the $\mathrm{TiN}-\mathrm{SiO}_{2}$ interfaces. This involved producing a gradual compositional transition over these regions, which could be undertaken readily using the flexible PACVD coating procedure. To ensure that this actually was the case the composition of the thin $(0.5 \mu \mathrm{m}$ thick $)$ TiON graded interfacial layer between the $2 \mu \mathrm{m}$ inner TiN and the $10 \mu \mathrm{m}$ thick outer silica coating on the nickel based superalloy IN639 was characterised. The only way in which the interlayer could be revealed readily was by precision taper sectioning a cross section through the coating and IN939 substrate. By this procedure the interlayer was clearly revealed and magnified by over a factor of 25 (Fig. 5a). This enabled EPMA of the TiN-SiO 2 interface, which established the smooth graduations, concurrently in opposite directions, of the oxygen and nitrogen concentrations within the TiON interlayer (Fig. 5b).
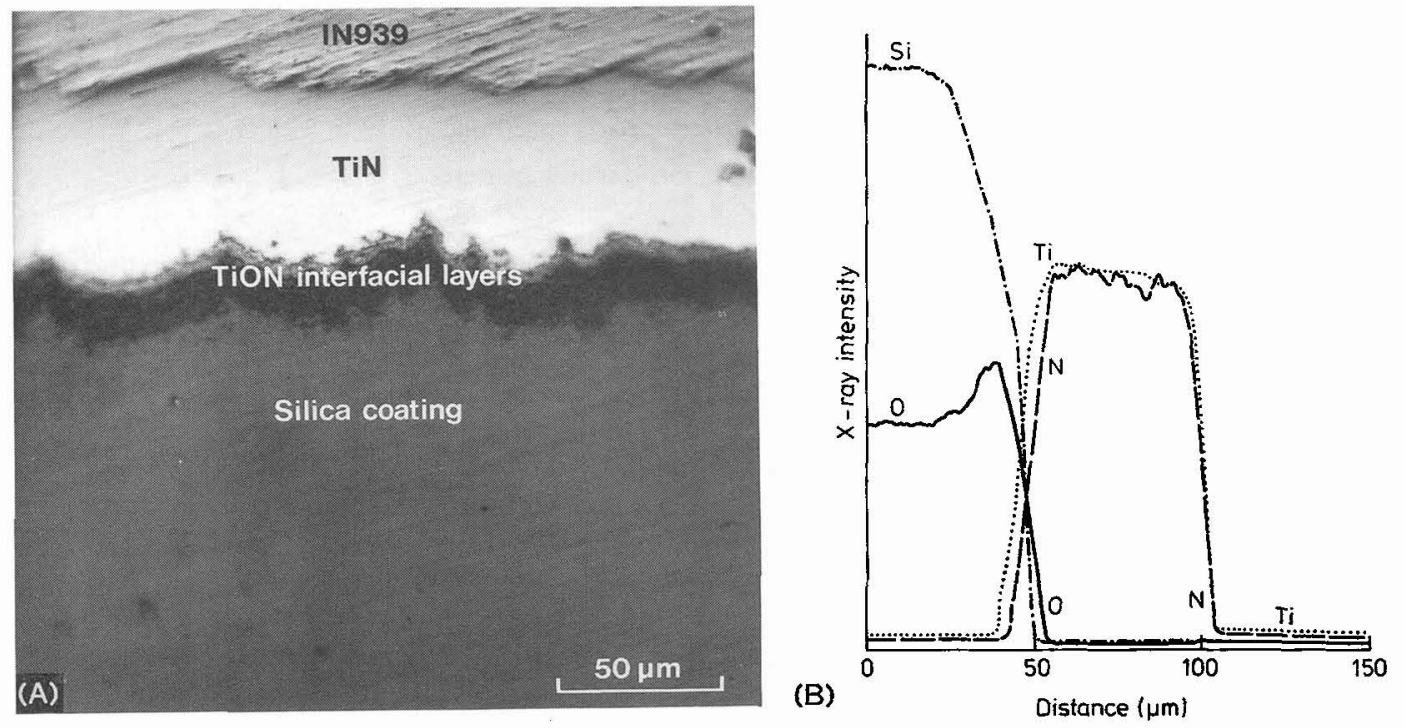

Fig. 5. - a) Secondary-electron image of a taper section through a PACVD $\mathrm{SiO}_{2}$-TiN coating, with a graded TiON interfacial layer, on IN939. b) The elemental distributions across the interlayer, as measured by EPMA.

3.2 EPMA ANALYSES OF A DOPED LAYER AT THE BASE OF SEMICONDUCTOR DEVICE TRENCHES $0.7 \mu \mathrm{m}$ DIAM. $\times 4 \mu \mathrm{m}$ DEEP. - Semiconductor device wafers, with an array of cylindrical trenches $(0.7 \mu \mathrm{m}$ diam. and $4 \mu \mathrm{m}$ deep), were produced with a phosphorous doped layer on the surface and at the base of the trenches. To verify predictions, based on the deposition parameters, analysis of the phosphorous content within the doped layer at the base of the trenches was required. This was clearly a considerable challenge in view of the geometry of the region to be sampled. Precision taper sectioning proved to be the most appropriate way to make the trench base accessible for analysis (Fig. 6a) and this was undertaken successfully by EPMA. The measurements required of the phosphorous variation across the trench are shown in figure $6 \mathrm{~b}$. 


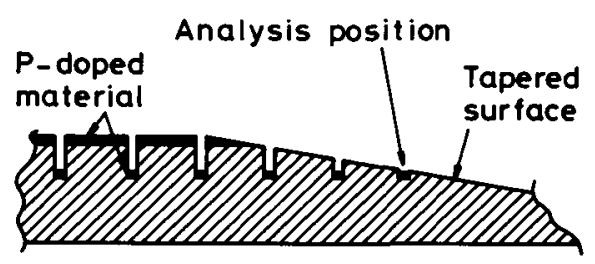

[A] Cross-section of tapered surface

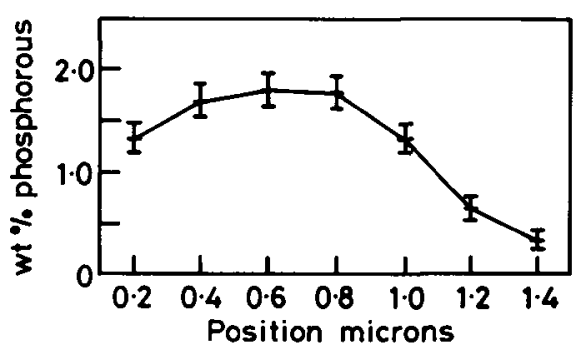

[B] Phosphorous variation across trench

Fig. 6. - Electron probe microanalysis of the phosphorous concentration at the base of cylindrical trenches $(0.7 \mu \mathrm{m}$ diam. $\times 4 \mu \mathrm{m}$ deep $)$ in semiconductor device wafers

3.3 CHROMIA SCALE GROWTH MECHANISM DURING GHROMIUM OXIDATION IN OXYGEN. Crucial to any understanding of the behaviour of protective oxide scales is knowledge of the mechanism by which they grow. The experimental technique employed by most researchers is based on sequential exposure to oxidants containing different ${ }^{18} \mathrm{O}$ isotope concentrations (usually normal, $0.2 \%$ and then enriched, $>97 \%$ ). This is then followed by analysis of the isotopic distributions through the scale, from which transport mechanisms of diffusing species can be deduced. Most studies have measured depth profiles of the average isotopic concentration with data being obtained by either nuclear reaction or SIMS analysis. However, greater mechanistic insight is provided by two-dimensional spatial information of the isotopic distributions, which can be provided by SIMS image analysis. Here precision taper sectioning has proved to be the indispensable preparation technique. The oxide scales produced are usually a few (typically 1-5) microns thick and although these need only to be slightly magnified to achieve optimum instrumental resolution, the main advantages of the taper sectioning procedure lie in the ability to produce clearly defined, parallel, flat polished transverse sections through the oxide scale and metallic substrate. This has ensured high quality image data acquisition with maximum efficiency. Preparation of scale cross-sections by this method has proved to be superior to those produced by other methods, e.g. ball-cratering, or the pit sides resulting from SIMS depth profiling.

As an example SIMS elemental images of a transverse section of a chromia scale formed on chromium during sequential oxidation in ${ }^{16} \mathrm{O}_{2}$ and then ${ }^{18} \mathrm{O}_{2}$, at $950{ }^{\circ} \mathrm{C}$, are shown in figure 7. The secondary electron and ${ }^{52} \mathrm{Cr}$ images (Figs. 7a, b) delineated the scale. Comparison of the ${ }^{16} \mathrm{O}$ and the ${ }^{18} \mathrm{O}$ ion images (Figs. $7 \mathrm{c}, \mathrm{d}$ ) indicate that the latter lay above the former. This would establish that the principal transport mechanism was outward $\mathrm{Cr}^{+3}$ movement. The two dimensional images also revealed other information that would not be 
so clearly apparent from basic depth profiles. This was the occurrence of ${ }^{18} \mathrm{O}$ and ${ }^{16} \mathrm{O}^{18} \mathrm{O}$ streaks into the scale formed in ${ }^{16} \mathrm{O}_{2}$, at a decreasing intensity with increasing depth from the $\mathrm{Cr}_{2}{ }^{16} \mathrm{O}_{3}-\mathrm{Cr}_{2}^{18} \mathrm{O}_{3}$ interface (Fig. 7d). The streaks occur at a distance of separation probably consistent with the oxide scale grain size. This would suggest that outward $\mathrm{Cr}^{3+}$ diffusion was accompanied by limited anion transport into, and exchange along, the oxide grain boundaries.

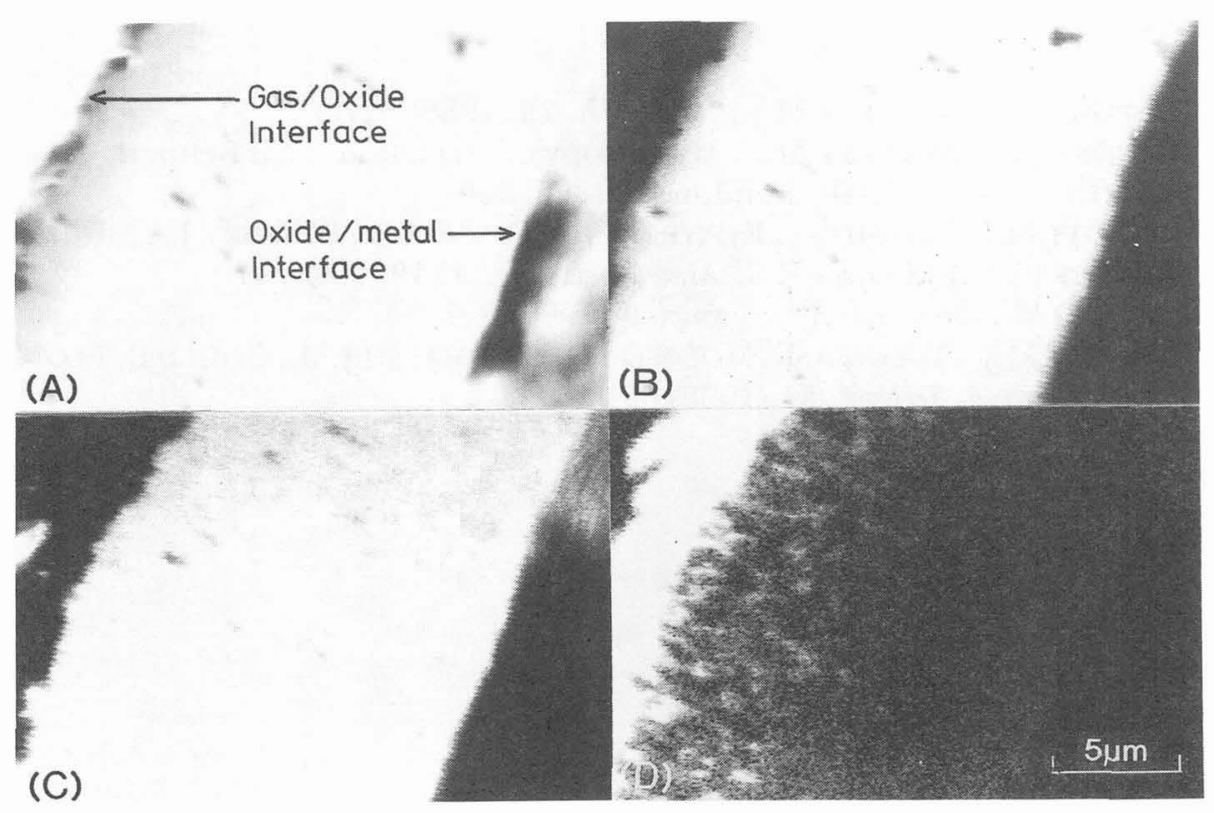

Fig. 7. - SIMS elemental images of a transverse section of a chromia scale formed on chromium during oxidation, at $950{ }^{\circ} \mathrm{C}$, for $45.75 \mathrm{~h} \mathrm{in}{ }^{16} \mathrm{O}_{2}$ and then for $20.25 \mathrm{~h}$ in ${ }^{18} \mathrm{O}_{2}$ : a) secondary electron image; b) ${ }^{52} \mathrm{Cr}^{+}$ion image; c) ${ }^{16} \mathrm{O}^{-}$ion image; d) ${ }^{18} \mathrm{O}^{-}$ion image (Log).

\section{Conclusions.}

The satisfactory preparation of specimens by surface microsurgery techniques is an essential pre-requisite for surface analysis. The more precise is specimen preparation, the more detail that can be revealed as to the composition and structure of surface layers, giving the opportunity also for the fullest possible exploitation of the capabilities of surface analytical instruments.

This study has demonstrated clearly that taper sectioning is a versatile surface microsurgery technique. The relative simple developments undertaken in both the required equipment and experimental processing enable this procedure to be undertaken readily and with assured maximum precision. The potential applications for this surface microsurgery technique are wide ranging, as demonstrated by the three examples discussed. 


\section{Acknowledgements.}

This work forms part of the Corporate Research and Development Programme of AEA Technology. We are grateful for the experimental assistance of our colleagues, C.F. Ayres, A.T. Tuson, D.P. Moon and D.M. Poole.

\section{References}

[1] Desport J.A., BenneTt M.J., Oxid. Met. 29 (1988) 327.

[2] DeSPORT J.A., BENNETT M.J., Microscopy of Oxidation, M.J. Bennett, G.W. Lorimer Eds. (Institute of Metals, London, 1991) p. 356

[3] BenNetT M.J., KNights C.F., AYRES C.F., TUSON A.T., DESPORT J.A., RiCKERBy D.S., SAUNDERS S.R.J., COLEY K.S., Mater. Sci. Eng. A139 (1991) 91.

[4] POOLE D.M., Semicond. Sci. Technol. 5 (1990) 625.

[5] Bennett M.J., Tuson A.T., MOON D.P., TitChMARSh J.M., GOUld P., Flower H.M., J. Surf. Coatings Technol. 51 (1992) 65. 